\title{
Predictors of Resilience Among Infants at Risk for Rapid Weight Gain
}

\author{
Alison K. Ventura (iD) and Kristen Thompson
}

Objective: The study objective was to investigate factors associated with resilience to rapid weight gain (RWG) among predominantly bottle-fed infants.

Methods: Data came from 1,353 mothers who participated in the Infant Feeding Practices Study 2. Mothers completed a prenatal questionnaire and monthly surveys of infant feeding and growth between birth and 12 months. Infants were classified as resilient if they were predominantly bottle fed but did not exhibit RWG between birth and the latter half of infancy ( $\geq+0.67$ change in weight-for-age $z$ score).

Results: Thirty-five percent of the sample $(n=467)$ was predominantly bottle fed but did not exhibit RWG ("Resilient"), $17 \%(n=228)$ was predominantly bottle fed and exhibited RWG ("Not Resilient"), and 49\% $(n=658)$ was not predominantly bottle fed ("Low Risk"). Significant predictors of resilience to RWG were greater gestational age $(P=0.042)$ and weight $(P<0.001)$ at birth, lower frequency of adding cereal to the bottle $(P=0.022)$, lower frequency of infant-led bottle-emptying $(P=0.047)$, and greater frequency of maternal encouragement of bottle-emptying $(P=0.002)$.

Conclusions: Associations between bottle-feeding and RWG may be moderated by infant characteristics and maternal feeding practices. The present study highlighted several characteristics of predominantly bottle-fed infants who were resilient to RWG, but further research is needed to identify a broader array of key targets for future intervention efforts.

\section{Introduction}

Rapid weight gain (RWG) during infancy is one of the earliest postnatal risk factors for the development of later obesity and metabolic dysfunction (1) and is therefore a prime target for prevention and intervention efforts $(2,3)$. Formula/bottle-feeding is a modifiable predictor of risk for RWG, with a growing body of research illustrating independent and combined effects of milk type (i.e., formula vs. breastmilk) and feeding mode (i.e., from a bottle vs. directly from the breast) on increasing infants' risk for overfeeding, impaired satiety responsiveness, and RWG (4-6).

Reduction of formula/bottle usage through promotion of breastfeeding is ideal and has been the focus of health promotion efforts (7). Despite continued focus on breastfeeding promotion, formula/bottle-feeding rates remain high (8-10). In $2015,16.8 \%$ of infants were exclusively formula fed from birth, with rates increasing to $42.4 \%$ of infants at 6 months of age (11). In addition, approximately $17.2 \%$ of breastfed infants were supplemented with formula within the first 2 days post partum, increasing to $28.8 \%$ at 3 months of age and $34.5 \%$ at 6 months of age (11). A paucity of secondary prevention efforts attempt to improve health outcomes for formula/bottle-feeding infants, and this research gap is amplified by findings that formula/bottle-feeding mothers report receiving inadequate support related to learning appropriate and healthy feeding practices (12).
It is also notable that not all formula/bottle-fed infants exhibit RWG (5). Previous research has illustrated that infants can effectively communicate satiation and regulate intake during infant-led bottle-feeding $(13,14)$ and that some mothers are responsive to infant cues during bottle-feeding interactions $(14,15)$. Therefore, the association between formula/bottle-feeding and RWG, although statistically significant, is not an absolute for all dyads and may be moderated by what both infants and mothers "bring to the table" during feeding interactions (14). Previous research has predominantly used a riskbased approach focused on identifying and removing risk factors, such as the use of formula and bottles via breastfeeding promotion; we instead propose a resilience-based perspective. The concept of resilience, or the process wherein an individual achieves healthy outcomes despite the presence of significant risk factors, has been applied within studies on a wide range of developmental outcomes, including mental health, socio-emotional development, and academic achievement (16-18). These studies have illustrated that positive outcomes are possible for children exposed to significant risk factors and can be promoted by protective factors that mitigate risk. A key benefit of a resilience perspective is the potential to provide an evidence base for strength-based approaches to obesity prevention efforts among high-risk groups (19). 
To this end, the aims of the current study are to identify predominantly formula/bottle-fed infants who were resilient to RWG across the first year and describe the combination of factors during early infancy (0-6 months of age) that characterize these infants, including characteristics of the infants (i.e., sex, gestational age, birth weight), the mothers (i.e., age, socioeconomic status, education, race/ethnicity, prepregnancy obesity, smoking during pregnancy), and infant feeding history or practices (i.e., frequency of breastmilk feeding, of putting the infant to bed with a bottle, of adding cereal to the bottle, of infant-led bottle-emptying, and of maternal encouragement of bottle-emptying; timing of introduction of complementary foods and beverages [CFB]; number of daily feedings).

\section{Methods \\ Participants}

We analyzed data from a subsample of the Infant Feeding Practices Study 2 (IFPS II), a study conducted by the Centers for Disease Control and Prevention and the Food and Drug Administration (20). Details about study methods have been published previously (21). Briefly, study participants were mothers in their third trimester of pregnancy recruited from a consumer opinion panel of $\sim 500,000$ US households. Inclusion criteria included to be a healthy woman $>18$ years of age, and the initial sample included $\sim 4,900$ pregnant women. Mothers were excluded from further assessments if they or their infants had medical conditions that affected feeding, if their infants were born before 35 weeks of gestation, or if their infants spent $>3$ days in the intensive care unit. Mothers were recruited through a prenatal questionnaire, which was mailed to all mothers in the panel who were $\sim 7$ months pregnant. A brief telephone interview occurred near the time of the infant's birth; all other assessments were collected via mailed questionnaires sent to mothers during their third trimester, then at 1, 2, 3, 4, 5, 6, 7, 9, 10, and 12 months post partum. As a secondary analysis of deidentified data, this present study was exempt from Institutional Review Board approval.

\section{Measures}

Infant diet, feeding practices, and eating behaviors. Mothers completed a food frequency questionnaire for their infants at all postpartum assessments. Mothers were asked to recall their infant's diet during the past 7 days, with specific prompts focused on the frequency of consumption of breastmilk, formula, and all other CFB.

As previously described by $\mathrm{Li}$ and colleagues (4,22,23), milk feeding practices were conceptualized in the following two ways: (1) bottle-feeding intensity, or the percentage of daily milk feedings from a bottle, and (2) breastmilk-feeding intensity, or the percentage of daily milk feedings that were breastmilk. To obtain these values, we first calculated the percentage of daily milk feedings that were breastmilk from the breast, expressed breastmilk from a bottle, and nonhuman milk at each assessment. Bottle-feeding intensity was then calculated as the proportion of milk feedings given by the bottle (percent expressed breastmilk from a bottle plus percent nonhuman milk), and breastmilk-feeding intensity was defined as the proportion of feedings containing breastmilk (percent breastmilk from the breast plus percent expressed breastmilk from a bottle). Consistent with previous research using the IFPS II data set (24), these values were then averaged across the first 6 months to obtain values for average bottle-feeding intensity and average breastmilk-feeding intensity during early infancy.

Infant age at introduction of CFB was determined as the age at which mothers first reported their infants consumed CFB. Each infant was then categorized as having "early" ( $<4$ months) or "recommended" ( $\geq 4$ months) timing of CFB introduction. As described above, data on CFB intake were limited to maternal reports of how often, in the past 7 days, infants were fed a variety of CFB; data on the amount consumed were not collected. At 6 months, mothers also reported the total number of daily feedings (including breastmilk, formula, and/or CFB, if applicable) to obtain an estimate of the amount of food eaten on a daily basis.

At each assessment, infant-led bottle-emptying, or the frequency with which the infant finished the bottle of breastmilk or formula, was assessed by two questions that referred to formula and expressed breastmilk feedings, respectively: "How often does your baby drink all of his or her bottle of formula?" and "How often does your baby drink all of his or her cup or bottle of pumped milk?" Similarly, maternal encouragement of bottle-emptying, or the frequency with which mothers encouraged their infants to finish the bottle, was assessed by two questions that referred to formula and expressed breastmilk feedings, respectively: "How often is your baby encouraged to finish the bottle if he or she stops drinking before the formula is all gone?" and "How often is your baby encouraged to finish a cup or bottle if he or she stops drinking before the pumped breastmilk is all gone?" Previous research using the IFPS II data set has used infant-led bottle-emptying as a proxy for low satiety responsiveness and/or high appetite (22-24) and maternal encouragement of bottle-emptying as a measure of pressuring feeding practices $(24,25)$. For all of these questions and at each assessment, mothers' responses to the formula and pumped milk versions of these two questions were averaged to create infant bottle-emptying and maternal encouragement of bottle-emptying scores. Mean maternal encouragement of bottle-emptying and infant-led bottle-emptying scores over the first six postpartum surveys were then calculated.

Mothers also reported the frequency with which they added cereal to their infant's bottle of formula or expressed breastmilk and the frequency with which they put their infant to bed with a bottle of formula or expressed breastmilk. Mean frequencies of adding cereal to the bottle and bottle-tobed scores over the first six postpartum surveys were calculated.

High-and low-risk bottle use groups. In our previous study (5), we conducted a group-based trajectory modeling (GBTM) analysis with the IFPS II data to identify distinct bottle-feeding-intensity trajectories across the first year post partum. Briefly, within our previous study (5), we used GBTM to estimate models with one to five groups representing differing patterns of bottle-feeding intensities across the first year post partum. Model selection criteria indicated that a four-group trajectory model best fit the data, as follows: (1) the "High-Stable Bottle Use Group" $(31.1 \%)$ reported that $\sim 100 \%$ of milk feedings were from bottles at all assessments; (2) the "Rapid Increase in Bottle Use Group" (19.4\%) reported low levels of bottle-feeding intensity during the neonatal assessment ( $\sim 30 \%$ of milk feedings) but a significant bottle usage increase to $\sim 100 \%$ of milk feedings at subsequent assessments; (3) the "Gradual Increase in Bottle Use Group" (24.6\%) had similarly low levels of bottle-feeding at early assessments and a more gradual increase in bottle-feeding intensity across the study period; and (4) the "Low-Stable Bottle Use Group" (24.9\%) had low levels of bottlefeeding $(<10 \%)$ at all assessments (5). The High-Stable Bottle Use and 
Rapid Increase in Bottle Use groups had significantly greater weight gain across infancy and higher weight-for-age $z$ scores (WAZs) at 12 months compared with the Gradual Increase in Bottle Use and LowStable Bottle Use groups (5). Therefore, for the present study, we used these same groups identified in our previous study and derived from our GBTM analysis, and we categorized infants in the High-Stable Bottle Use and Rapid Increase in Bottle Use groups as the "High Risk Bottle Use Group" ("High Risk") and infants in the Gradual Increase in Bottle Use and Low-Stable Bottle Use groups as the "Low Risk Bottle Use Group" ("Low Risk").

RWG. Mothers reported infant birth weight and length measurements. Additionally, within the assessments at 3, 5, 7, and 12 months, mothers reported their infant's measured weight and length at their last pediatrician visit. Weight measurements were standardized to age- and sex-specific WAZs based on the World Health Organization Child Growth Standards (26). Outliers (WAZ greater than 5 or less than -5 ) were eliminated because of biological implausibility. All infants included in the present study had data on birth weight and at least two other weight measurements, but because the timing of these measurements varied from infant to infant, RWG between birth and later infancy was defined as the difference between WAZ from birth to the last weight assessment between 6 and 12 months of age. RWG was then defined as WAZ change $\geq+0.67$ (27).

Resilience to $R W G$. Infants who were resilient to RWG were determined by calculating the proportion of the High Risk group who did versus did not exhibit RWG. Then infants were classified as follows: (1) "Resilient" (High Risk and no RWG), (2) "Not Resilient" (High Risk and RWG), and (3) "Low Risk."

Sociodemographic correlates. Maternal and familial demographic characteristics were assessed in the prenatal survey. Consistent with previous research that has used the IFPS II data set, the following variables were explored as potential correlates of resilience to RWG $(4,22,23)$ : infant sex and gestational age as well as maternal age, prepregnancy obesity, smoking status (smoker vs. not), parity, poverty-income ratio (defined as a ratio of household income to the poverty threshold by household size), postpartum participation in the Special Supplemental Nutrition Program for Women, Infants, and Children (WIC) program, race/ethnicity, and education.

\section{Statistical analyses}

All analyses were conducted using SAS version 9.4 (SAS Institute Inc., Cary, North Carolina). Participants were excluded for the following reasons: (1) mother was away from her infant more than 70 hours per week at any assessment, (2) mother reported that the infant had a serious health problem at any age, and (3) missing data on any of the predictor or outcome variables. The final analytical sample included 1,353 participants.

Descriptive information was generated for all variables of interest, and each outcome variable was assessed for normality. ANOVA with a general linear model and $\chi^{2}$ was used to assess differences among Resilient, Not Resilient, and Low Risk groups for infant and mother characteristics and family demographics. Variables associated with resilience to RWG were then evaluated using a binomial logistic regression model limited to infants who were High Risk for RWG to compare the Resilient versus Not Resilient groups. Within this logistic regression model, we included variables that represented (1) characteristics of the infant (sex, gestational age, and birth weight), (2) characteristics of the mother (age, prepregnancy obesity, smoking during pregnancy, parity, poverty-income ratio, WIC participation, education level, race/ ethnicity), and (3) aspects of infant feeding during early infancy (breastmilk-feeding intensity, frequency with which the infant was put to bed with a bottle, frequency with which the mother put cereal in the bottle, frequency of infant-led bottle-emptying, frequency of maternal encouragement of infant bottle-emptying, whether CFB were introduced early or in line with recommendations, and total number of daily feedings at 6 months). Descriptive statistics are presented as means \pm SDs or percentages $(n)$. Logistic regression results are presented as the odds of group membership and associated $95 \%$ CIs in each level of categorical explanatory variables relative to the specified reference category, or per unit change in continuous variables. $P<0.05$ indicated significant effects.

\section{Results}

\section{Sample characteristics}

Thirty-five percent of the sample $(n=467)$ had high-risk patterns of bottle-feeding but did not exhibit RWG (Resilient), 17\% $(n=228)$ had high-risk patterns of bottle-feeding and exhibited RWG (Not Resilient), and 49\% ( $n=658)$ was classified as Low Risk. As illustrated in Table 1, average WAZ change from birth to the latter half of infancy for Resilient infants was significantly less than average WAZ change for Not Resilient infants $(P<0.001)$ but was also significantly different from Low Risk infants $(P=0.029)$.

TABLE 1 Mean (SD) values for infants' weight-for-age $z$ score (WAZ) change

\begin{tabular}{|c|c|c|c|c|}
\hline & $\begin{array}{c}\text { Low Risk } \\
(n=658), 48.6 \%\end{array}$ & $\begin{array}{c}\text { Resilient } \\
(n=467), 34.5 \%\end{array}$ & $\begin{array}{c}\text { Not Resilient } \\
(n=228), 16.9 \%\end{array}$ & $P$ value \\
\hline Birth WAZ & $\begin{array}{r}0.40^{\mathrm{a}} \\
(0.90)\end{array}$ & $\begin{array}{l}0.61^{\mathrm{b}} \\
(0.82)\end{array}$ & $\begin{array}{r}-0.35^{c} \\
(0.79)\end{array}$ & $<0.001$ \\
\hline $\begin{array}{l}\text { Last WAZ during the latter } \\
\text { half of infancy* }\end{array}$ & $\begin{array}{c}0.08^{\mathrm{a}} \\
(1.18)\end{array}$ & $\begin{array}{r}0.16^{\mathrm{a}} \\
(0.96)\end{array}$ & $\begin{array}{r}1.13^{b} \\
(0.89)\end{array}$ & $<0.001$ \\
\hline WAZ change $^{\dagger}$ & $\begin{array}{r}-0.31^{\mathrm{a}} \\
(1.24)\end{array}$ & $\begin{array}{r}-0.45^{b} \\
(0.88)\end{array}$ & $\begin{array}{r}1.48^{\mathrm{C}} \\
(0.70)\end{array}$ & $<0.001$ \\
\hline
\end{tabular}

Means with different superscripts are significantly different at $P<0.05$.

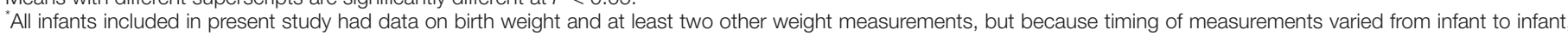
the last WAZ measurement was determined from last weight assessment during latter half of infancy (i.e., between 6 and 12 months of age).

${ }^{\dagger}$ Calculated as difference between WAZ from birth to latter half of infancy (i.e., last WAZ assessment between 6 and 12 months of age). 
Initial descriptive analyses revealed that Resilient infants could be distinguished from both other groups in a number of ways (Table 2). Resilient infants were born at a significantly greater gestational age $(\mathrm{F}[1,1,352]=24.27 ; P<0.001)$ and higher birth weight $(\mathrm{F}[1$, $1,352]=90.69 ; P<0.001)$ than both other groups. With respect to maternal characteristics, a significantly greater proportion of mothers of infants in the Resilient group had obesity prior to pregnancy compared with the Low Risk group $\left(\chi^{2}=6.52 ; P=0.038\right)$. A greater proportion of mothers of Resilient and Not Resilient infants smoked during pregnancy $\left(\chi^{2}=53.51 ; P<0.001\right)$, were primiparous $\left(\chi^{2}=13.33 ; P=0.001\right)$, participated in WIC $\left(\chi^{2}=34.13 ; P<0.001\right)$, and had low levels of education $\left(\chi^{2}=36.08 ; P<0.001\right)$ compared with mothers of Low Risk infants.
Compared with Low Risk infants, both Resilient and Not Resilient infants had significantly lower levels of breastmilk-feeding intensity ( $F[1$, $1,352]=2,625.73 ; P<0.001)$. Significantly greater proportions of both Resilient and Not Resilient infants were introduced to CFB early $(<4$ months of age) compared with Low Risk infants $\left(\chi^{2}=117.13 ; P<0.001\right)$, and mothers of infants in both the Resilient and Not Resilient groups reported significantly lower frequency of feedings when their infants were 6 months of age $(\mathrm{F}[1,1,352]=63.68 ; P<0.001)$. Mothers of both Resilient and Not Resilient infants also reported significantly greater frequency of adding cereal to the bottle $(\mathrm{F}[1,1,352]=80.47 ; P<0.001)$, infant-led bottle-emptying $(\mathrm{F}[1,1,352]=69.29 ; P<0.001)$, and maternal encouragement of bottle-emptying $(\mathrm{F}[1,1,352]=25.52 ; P<0.001)$ compared with mothers of infants in the Low Risk group (data not shown).

TABLE 2 Percentages $(n)$ or mean (SD) for group characteristics $(n=1,353)$

\begin{tabular}{|c|c|c|c|c|}
\hline & $\begin{array}{c}\text { Low Risk } \\
(n=658), 48.6 \%\end{array}$ & $\begin{array}{c}\text { Resilient } \\
(n=467), 34.5 \%\end{array}$ & $\begin{array}{c}\text { Not Resilient } \\
(n=228), 16.9 \%\end{array}$ & $P$ value \\
\hline \multicolumn{5}{|l|}{ Infant characteristics } \\
\hline Sex, percent female & $\begin{array}{l}48.8 \\
(321)\end{array}$ & $\begin{array}{l}51.8 \\
(242)\end{array}$ & $\begin{array}{r}47.8 \\
(109)\end{array}$ & 0.499 \\
\hline Gestational age, wk & $\begin{array}{l}39.4^{\mathrm{a}} \\
(1.2)\end{array}$ & $\begin{array}{l}39.5^{b} \\
(1.1)\end{array}$ & $\begin{array}{l}38.9^{c} \\
(1.4)\end{array}$ & $<0.001$ \\
\hline Birth weight, lb & $\begin{array}{l}7.7^{\mathrm{a}} \\
(1.0)\end{array}$ & $\begin{array}{l}7.9^{b} \\
(0.9)\end{array}$ & $\begin{array}{l}6.9^{c} \\
(0.8)\end{array}$ & $<0.001$ \\
\hline \multicolumn{5}{|l|}{ Maternal characteristics } \\
\hline Age at study entry, y & $\begin{array}{l}30.3^{\mathrm{a}} \\
(5.0)\end{array}$ & $\begin{array}{l}29.7^{b} \\
(5.3)\end{array}$ & $\begin{array}{l}29.5^{b} \\
(5.5)\end{array}$ & 0.047 \\
\hline Percent with prepregnancy obesity & $\begin{array}{l}21.9^{a} \\
(144)\end{array}$ & $\begin{array}{l}28.5^{b} \\
(133)\end{array}$ & $\begin{array}{c}25.9^{a b} \\
(59)\end{array}$ & 0.038 \\
\hline Percent smoked during pregnancy & $\begin{array}{l}7.75^{a} \\
(51)\end{array}$ & $\begin{array}{c}20.6^{b} \\
(96)\end{array}$ & $\begin{array}{l}24.1^{b} \\
(55)\end{array}$ & $<0.001$ \\
\hline Percent primiparious & $\begin{array}{l}24.6^{a} \\
(162)\end{array}$ & $\begin{array}{l}32.3^{b} \\
(151)\end{array}$ & $\begin{array}{c}35.5^{\mathrm{b}} \\
(81)\end{array}$ & 0.001 \\
\hline PIR level, percent of poverty level & $\begin{array}{c}287.6 \\
(190.5)\end{array}$ & $\begin{array}{l}297.8 \\
(217.3)\end{array}$ & $\begin{array}{l}278.7 \\
(210.4)\end{array}$ & 0.478 \\
\hline Percent WIC participation & $\begin{array}{l}23.5^{\mathrm{a}} \\
(155)\end{array}$ & $\begin{array}{l}36.2^{b} \\
(169)\end{array}$ & $\begin{array}{r}41.2^{b} \\
(94)\end{array}$ & $<0.001$ \\
\hline Percent high school degree or less & $\begin{array}{c}10.8^{a} \\
(71)\end{array}$ & $\begin{array}{l}21.8^{b} \\
(102)\end{array}$ & $\begin{array}{l}25.0^{b} \\
(57)\end{array}$ & $<0.001$ \\
\hline Percent minority race/ethnicity & $\begin{array}{c}10.6^{\mathrm{a}} \\
(70)\end{array}$ & $\begin{array}{l}11.1^{\mathrm{a}} \\
(52)\end{array}$ & $\begin{array}{l}17.5^{\mathrm{b}} \\
(40)\end{array}$ & 0.017 \\
\hline \multicolumn{5}{|l|}{ Infant feeding characteristics } \\
\hline $\begin{array}{l}\text { Average bottle-feeding intensity, } \\
0 \text { to } 6 \text { months }\end{array}$ & $\begin{array}{r}12.7^{\mathrm{a}} \\
(12.9)\end{array}$ & $\begin{array}{l}87.8^{b} \\
(19.6)\end{array}$ & $\begin{array}{l}88.2^{b} \\
(19.7)\end{array}$ & $<0.001$ \\
\hline $\begin{array}{l}\text { Average breastmilk-feeding intensity, } \\
0 \text { to } 6 \text { months }\end{array}$ & $\begin{array}{l}79.7^{\mathrm{a}} \\
(18.2)\end{array}$ & $\begin{array}{l}11.1^{b} \\
(17.6)\end{array}$ & $\begin{array}{c}9.5^{b} \\
(15.3)\end{array}$ & $<0.001$ \\
\hline Percent introduced CFB early ( $<4$ months) & $\begin{array}{l}33.8^{a} \\
(222)\end{array}$ & $\begin{array}{l}62.5^{b} \\
(292)\end{array}$ & $\begin{array}{l}63.6^{b} \\
(145)\end{array}$ & $<0.001$ \\
\hline Daily frequency of feeding at 6 months & $\begin{array}{l}6.0^{\mathrm{a}} \\
(1.1)\end{array}$ & $\begin{array}{l}5.3^{b} \\
(1.2)\end{array}$ & $\begin{array}{l}5.3^{\mathrm{b}} \\
(1.3)\end{array}$ & $<0.001$ \\
\hline
\end{tabular}

Means with different superscripts are significantly different at $P<0.05$.

CFB, complementary foods and beverages; PIR, poverty-income ratio; WIC, Special Supplemental Nutrition Program for Women, Infants, and Children. 


\section{Predictors of resilience among High Risk infants}

Table 3 presents results for the logistic regression model limited to the subgroup of High Risk infants $(n=695)$ to identify the combination of variables that distinguished High Risk infants who were versus were not resilient to RWG. Significant predictors of resilience to RWG among High Risk infants were greater gestational age $(P=0.042)$ and weight $(P<0.001)$ at birth, lower frequency of adding cereal to the bottle $(P=0.022)$, lower frequency of infant-led bottle-emptying $(P=0.047)$, and greater frequency of maternal encouragement of bottle-emptying $(P=0.002)$.

TABLE 3 Binomial logistic regression predicting resilience to RWG among High Risk infants $(n=695)$

\begin{tabular}{|c|c|}
\hline & $\begin{array}{l}\text { Resilient }{ }^{\mathrm{a}} \text { (“High } \\
\text { Risk" and no RWG) }\end{array}$ \\
\hline \multicolumn{2}{|l|}{ Infant characteristics } \\
\hline Sex (reference = girl) & $0.68(0.46-1.00)$ \\
\hline Gestational age & $1.19(1.01-1.40)^{\star}$ \\
\hline Birth weight & $4.03(3.07-5.28)^{\star \star *}$ \\
\hline \multicolumn{2}{|l|}{ Maternal characteristics } \\
\hline Age & $1.00(0.95-1.04)$ \\
\hline $\begin{array}{l}\text { Prepregnancy obesity } \\
\text { (reference }=\text { normal weight or with } \\
\text { overweight) }\end{array}$ & $0.97(0.63-1.50)$ \\
\hline $\begin{array}{l}\text { Smoking during pregnancy (refer- } \\
\text { ence = no smoking) }\end{array}$ & $1.32(0.67-2.60)$ \\
\hline Primiparity (reference = multiparous) & $0.93(0.60-1.44)$ \\
\hline PIR level & $1.00(0.99-1.01)$ \\
\hline $\begin{array}{l}\text { WIC participation } \\
\text { (reference }=\text { no participation) }\end{array}$ & $1.23(0.76-2.00)$ \\
\hline $\begin{array}{l}\text { Education level } \\
\text { (reference = some college) }\end{array}$ & $0.83(0.51-1.38)$ \\
\hline Race/ethnicity (reference = white) & $0.79(0.45-1.40)$ \\
\hline \multicolumn{2}{|l|}{ Infant feeding characteristics } \\
\hline Breastmilk-feeding intensity ${ }^{\mathrm{b}, \mathrm{c}}$ & $1.01(1.00-1.02)$ \\
\hline Frequency of bottle-to-bed ${ }^{c}$ & $0.89(0.75-1.05)$ \\
\hline Frequency of cereal in bottle ${ }^{c}$ & $0.82(0.69-0.97)^{*}$ \\
\hline $\begin{array}{l}\text { Frequency of infant-led } \\
\text { bottle-emptying }\end{array}$ & $0.66(0.44-1.00)^{*}$ \\
\hline $\begin{array}{l}\text { Frequency of maternal } \\
\text { encouragement of bottle-emptying }\end{array}$ & $1.34(1.11-1.61)^{\star *}$ \\
\hline Early introduction of $\mathrm{CFB}^{\mathrm{C}}$ & $1.20(0.78-1.86)$ \\
\hline Frequency of feedings $^{\mathrm{d}}$ & $0.98(0.84-1.14)$ \\
\hline \multicolumn{2}{|c|}{$\begin{array}{l}\text { adds of group membership compared with "Not Resilient" ("High Risk" and RWG } \\
\text { reference group. } \\
\text { bDefined as number of daily breastmilk feedings divided by total number of milk feed } \\
\text { ings times } 100 \text {. } \\
\text { cAverage score across neonatal and month } 2,3,4,5 \text {, and } 6 \text { assessments. } \\
\text { dAssessed at } 6 \text { months. } \\
\text { " } P<0.05 \text {. } \\
\text { " } P<0.01 \text {. } \\
\text { "' } P<0.001 \text {. } \\
C F B \text {, complementary foods and beverages; PIR, poverty-income ratio; RWG, rapic } \\
\text { weight gain; WIC, Special Supplemental Nutrition Program for Women, Infants, and } \\
\text { Children. }\end{array}$} \\
\hline
\end{tabular}

\section{Discussion}

A striking paucity of studies have explored predictors of healthy weight-gain trajectories for infants who are formula/bottle fed. To this end, the aims of the present study were to identify predominantly formula/bottle-fed infants who were resilient to RWG during the first year post partum and to describe the combination of infant and maternal characteristics and behaviors associated with resilience. Key predictors of resilience were greater gestational age and weight at birth, lower frequency of infant-led bottle-emptying, lower frequency of adding cereal to the bottle, and greater frequency of maternal encouragement of bottle-emptying during the first 6 months post partum.

Individual variation in gestational age and weight at birth is influenced, in part, by preconception and prenatal factors that affect interuterine growth and birth outcomes, such as maternal smoking, preconception weight status, and gestational weight gain $(28,29)$. Our finding that infants with higher birth weight and greater gestational age were at lower risk for RWG is not entirely surprising given well-documented differences in rates of postnatal growth for infants who are smaller versus larger at birth (30). However, it was somewhat surprising that a greater proportion of mothers of resilient infants had obesity prior to pregnancy compared with mothers of low-risk infants. Although previous research has illustrated that mothers who have overweight or obesity prior to pregnancy are at increased risk for having infants with greater birth weights (31), similar connections between maternal prepregnancy obesity and infants' increased risk for RWG have also been documented $(32,33)$. Additional research is needed to better understand associations between preconception and prenatal factors and infants' risk for RWG; however, one possible implication of the present findings is that primary prevention efforts should target preconception and prenatal factors to help promote appropriate gestational age and birth weight, thus promoting a proper foundation for slower rates of weight gain during the first year.

Previous research using the IFPS II data set has used infant-led bottle-emptying as a proxy for low satiety responsiveness and/or high appetite (22-24); a limitation to this interpretation is that frequency of infant-led bottle-emptying was not measured within the context of how much milk or formula was offered. However, greater frequency of infant-led bottle-emptying predicts lower satiety responsiveness at 6 years (24), suggesting that it may be an effective proxy. Our finding that lower frequency of infant-led bottle-emptying was associated with greater odds of resilience to RWG is consistent with previous research suggesting that self-regulation of intake $(34,35)$ and lower appetitive drive (36) during infancy may protect against excess weight gain during infancy and promote healthier weight status during later childhood.

Responsive feeding practices and styles are theorized to be key supports for infants' developing abilities to self-regulate intake (37), and promotion of responsive feeding has been the focus of recent interventions $(38,39)$ and recommendations $(2,3)$ related to preventing RWG during infancy. A limitation of the present study is that the IFPS II did not include a validated measure of maternal feeding practices and styles, which hindered our ability to effectively explore feeding practices and styles as a correlate of resilience. Available measures of feeding practices within the IFPS II included putting the infant to bed with a bottle, addition of cereal to the bottle, and maternal encouragement of infant bottle-emptying. Our finding that mothers of resilient infants reported lower frequency of added cereal is consistent with previous research linking 
this feeding practice with excess infant weight gain (40) and implicates this feeding practice as a potential target for future intervention efforts. However, it is likely that the greater encouragement of infant bottle-emptying among mothers of resilient infants reflects mothers' concerns for their infant's weight status and desire to promote weight gain rather than an effect of encouraging bottle-emptying on lowered risk for RWG. Given previous research linking maternal encouragement of bottle-emptying to mothers' use of more controlling feeding practices and poorer child satiety responsiveness when children are 6 years old (24), further research is needed to understand mothers' motivations for encouraging bottle-emptying and longer-term outcomes for infants who were resilient to RWG despite mothers' use of pressuring feeding practices.

Additional study limitations highlight opportunities for further research. The present study was limited by the fact that the IFPS II sample was relatively low risk and was not nationally representative of the US population. Additionally, our use of observational data limits our ability to understand causal mechanisms. We chose to define RWG as WAZ change $\geq+0.67$ because this definition has been widely used in previous research (27). However, a possible limitation of this definition is that it highlights infants who exhibit upward crossing between major percentile lines on infant growth charts (e.g., the 50th to 75th) and thus may only capture infants with very large positive changes in WAZ. Although there has been significant evidence for the predictive validity of this definition of RWG (27), further research that examines implications of lesser degrees of RWG may be informative.

\section{Conclusion}

Bottle-feeding is a ubiquitous part of infant feeding, yet few studies focus on promoting healthy feeding interactions and growth trajectories for bottle-fed infants. Bottle-feeding caregivers need better support to reduce the use of undesirable practices (e.g., placing cereal in bottle, encouraging infant bottle-emptying) and adopt desirable practices (e.g., bottle-feeding that is responsive to infant hunger and satiation cues) that may moderate their infant's heightened risk for RWG. A resilience-based approach allows for identification of strengths and effective practices that support optimal outcomes for predominantly bottle-fed infants. The present study highlighted several characteristics of predominantly bottle-fed infants who were resilient to RWG, but further research is needed to identify a broader array of key targets for future intervention efforts. $\mathbf{O}$

\section{Acknowledgments}

We thank the mothers and infants who participated in this study. We also thank Sierra Sheeper and Jordyn Levy for their technical assistance.

\section{References}

1. Zheng M, Lamb KE, Grimes C, et al. Rapid weight gain during infancy and subsequent adiposity: a systematic review and meta-analysis of evidence. Obes Rev 2018;19:321-332.

2. Lumeng JC, Taveras EM, Birch L, Yanovski SZ. Prevention of obesity in infancy and early childhood: a National Institutes of Health workshop. JAMA Pediatr 2015;169:484-490.

3. Institute of Medicine. Birch LL, Parker L, Burns A, eds. Early Childhood Obesity Prevention Policies. Washington, DC: National Academies Press; 2011.
4. Li R, Magadia J, Fein SB, Grummer-Strawn LM. Risk of bottle-feeding for rapid weight gain during the first year of life. Arch Pediatr Adolesc Med 2012;166:431-436.

5. Ventura AK. Developmental trajectories of bottle-feeding during infancy and their association with weight gain. J Dev Behav Pediatr 2017;38:109-119.

6. Weng SF, Redsell SA, Swift JA, Yang M, Glazebrook CP. Systematic review and meta-analyses of risk factors for childhood overweight identifiable during infancy. Arch Dis Child 2012;97:1019-1026.

7. Office of the Surgeon General; Centers for Disease Control and Prevention; Office on Women's Health. The Surgeon General's Call to Action to Support Breastfeeding. Rockville, MD: Office of the Surgeon General; 2011.

8. Grummer-Strawn LM, Scanlon KS, Fein SB. Infant feeding and feeding transitions during the first year of life. Pediatrics 2008;122(suppl 2):S36-S42.

9. Shealy KR, Scanlon KS, Labiner-Wolfe J, Fein SB, Grummer-Strawn LM Characteristics of breastfeeding practices among US mothers. Pediatrics 2008;122(suppl 2):S50-S55.

10. Labiner-Wolfe J, Fein SB, Shealy KR, Wang C. Prevalence of breast milk expression and associated factors. Pediatrics 2008;122(suppl 2):S63-S68.

11. Centers for Disease Control and Prevention. Breastfeeding report card. https://www. cdc.gov/breastfeeding/data/reportcard.htm. Accessed September 15, 2018. Updated August 20, 2018

12. Lakshman R, Ogilvie D, Ong KK. Mothers' experiences of bottle-feeding: a systematic review of qualitative and quantitative studies. Arch Dis Child 2009;94:596-601.

13. Ventura AK, Inamdar LB, Mennella JA. Consistency in infants' behavioural signalling of satiation during bottle-feeding. Pediatr Obes 2015;10:180-187.

14. Ventura AK, Mennella JA. An experimental approach to study individual differences in infants' intake and satiation behaviors during bottle-feeding. Child Obes 2017; $13: 44-52$

15. Ventura AK, Pollack Golen R. A pilot study comparing opaque, weighted bottles with conventional, clear bottles for infant feeding. Appetite 2015;85:178-185.

16. Werner EE, Smith RS. Vulnerable but Invincible: A Study of Resilient Children. New York: McGraw Hill; 1982.

17. Lunthar SS, Cicchetti D, Becker B. The construct of resilience: A critical evaluation and guidelines for future work. Child Dev 2000;71:543-562.

18. Masten AS. Ordinary magic: resilience processes in development. Am Psychol 2001;56:227-238.

19. Ball K, Crawford D. Socio-economic factors in obesity: a case of slim chance in a fat world? Asia Pac J Clin Nutr 2006;15:15-20.

20. Centers for Disease Control and Prevention. Breastfeeding and infant feeding practices. https://www.cdc.gov/breastfeeding/data/ifps/index.htm. Accessed September 17, 2018. Updated December 1, 2017.

21. Fein SB, Labiner-Wolfe J, Shealy KR, Li R, Chen J, Grummer-Strawn LM. Infant Feeding Practices Study II: study methods. Pediatrics 2008;122(suppl 2):S28-S35.

22. Li R, Fein SB, Grummer-Strawn LM. Association of breastfeeding intensity and bottle-emptying behaviors at early infancy with infants' risk for excess weight at late infancy. Pediatrics 2008;122(suppl 2):S77-S84.

23. Li R, Fein SB, Grummer-Strawn LM. Do infants fed from bottles lack self-regulation of milk intake compared with directly breastfed infants? Pediatrics 2010;125:e1386-e1393.

24. Li R, Scanlon KS, May A, Rose C, Birch L. Bottle-feeding practices during early infancy and eating behaviors at 6 years of age. Pediatrics 2014;134:S70-77.

25. Ventura AK, Garcia P, Schaffner AA. Associations between bottle-feeding intensity and maternal encouragement of bottle-emptying. Public Health Nutr 2017;20:3090-3098.

26. World Health Organization. WHO Child Growth Standards: Length/height-for-age, weight-for-age, weight-for-length, weight-for-height and body mass index-for-age. Methods and Development. Geneva, Switzerland: WHO; 2006.

27. Ong KK, Loos RJ. Rapid infancy weight gain and subsequent obesity: systematic reviews and hopeful suggestions. Acta Paediatr 2006;95:904-908.

28. Harrod CS, Fingerlin TE, Chasan-Taber L, Reynolds RM, Glueck DH, Dabelea D. Exposure to prenatal smoking and early-life body composition: the healthy start study. Obesity (Silver Spring) 2015;23:234-241.

29. Pizzi C, Cole TJ, Richiardi L, dos-Santos-Silva I, Corvalan C, De Stavola B. Prenatal influences on size, velocity and tempo of infant growth: findings from three contemporary cohorts. PLoS One 2014;9:e90291. doi:10.1371/journal.pone.0090291

30. Singhal A. Long-term adverse effects of early growth acceleration or catch-up growth Ann Nutr Metab 2017;70:236-240.

31. Yu Z, Han S, Zhu J, Sun X, Ji CY, Guo X. Pre-pregnancy body mass index in relation to infant birth weight and offspring overweight/obesity: A systematic review and meta-analysis. PLoS One 2013;8:e61627. doi:10.1371/journal.pone.0061627

32. Heerman WJ, Bian A, Shintani A, Barkin SL. Interaction between maternal prepregnancy body mass index and gestational weight gain shapes infant growth. Acad Pediatr 2014;14:463-470

33. Jin WY, Lv Y, Bao Y, et al. Independent and combined effects of maternal prepregnancy body mass index and gestational weight gain on offspring growth at $0-3$ years of age. Biomed Res Int 2016;2016:4720785. doi:10.1155/2016/4720785

34. Fomon SJ, Filer LJ Jr, Thomas LN, Rogers RR, Proksch AM. Relationship between formula concentration and rate of growth of normal infants. J Nutr 1969;98:241-254.

35. Dewey KG, Lönnerdal B. Infant self-regulation of breast milk intake. Acta Paediatr Scand 1986;75:893-898.

36. Agras WS, Kraemer HC, Berkowitz RI, Korner AF, Hammer LD. Does a vigorous feeding style influence early development of adiposity? J Pediatr 1987;110:799-804.

37. DiSantis KI, Hodges EA, Johnson SL, Fisher JO. The role of responsive feeding in overweight during infancy and toddlerhood: a systematic review. Int J Obes (Lond) 2011;35:480-492. 
38. Savage JS, Birch LL, Marini M, Anzman-Frasca S, Paul IM. Effect of the INSIGHT responsive parenting intervention on rapid infant weight gain and overweight status at age 1 year: a randomized clinical trial. JAMA Pediatr 2016;170:742-749.

39. Daniels LA, Magarey A, Battistutta D, et al. The NOURISH randomised control trial: positive feeding practices and food preferences in early childhood - a primary prevention program for childhood obesity. BMC Public Health 2009;9:387. doi:10.1186/1471-2458-9-387

40. Almquist-Tangen G, Dahlgren J, Roswall J, Bergman S, Alm B. Milk cereal drink increases BMI risk at 12 and 18 months, but formula does not. Acta Paediatr 2013;102:1174-1179. 